\title{
Bottom pressure tides along a line in the southeast Atlantic Ocean and comparisons with satellite altimetry
}

\author{
Richard D. Ray · Deirdre A. Byrne
}

Received: 12 March 2010/ Accepted: 2 July 2010/ Published online: 25 July 2010

(c) US Government 2010

\begin{abstract}
Seafloor pressure records, collected at 11 stations aligned along a single ground track of the Topex/Poseidon and Jason satellites, are analyzed for their tidal content. With very low background noise levels and approximately 27 months of high-quality records, tidal constituents can be estimated with unusually high precision. This includes many high-frequency lines up through the seventh-diurnal band. The station deployment provides a unique opportunity to compare with tides estimated from satellite altimetry, point by point along the satellite track, in a region of moderately high mesoscale variability. That variability can significantly corrupt altimeter-based tide estimates, even with 17 years of data. A method to improve the alongtrack altimeter estimates by correcting the data for nontidal variability is found to yield much better agreement with the bottom-pressure data. The technique should prove useful in certain demanding applications, such as altimetric studies of internal tides.
\end{abstract}

Responsible Editor: Dirk Olbers

R. D. Ray ( $\square)$
NASA Goddard Space Flight Center, Greenbelt, MD, USA
e-mail: richard.ray@nasa.gov

D. A. Byrne

School of Marine Sciences, University of Maine,

Orono, ME, USA

e-mail: dbyrne@umeoce.maine.edu
Keywords Oceanic tides - Satellite altimetry • Ocean bottom pressure

\section{Introduction}

Since their earliest deployments in the deep ocean, bottom pressure recorders (BPR) have been usefully employed to study tides. Thirty years ago they afforded the only means to determine the tide in mid-ocean regions remote from islands (Cartwright et al. 1980). Since the advent of satellite altimetry, they have been invaluable for validating and comparing tidal models (e.g., Cartwright and Ray 1990; Shum et al. 1997). Other tidal applications range from studying internal tides (typically in conjunction with echo sounders, e.g., Park and Watts 2006) to determining the frequency response of the solid-Earth tide (Ray et al. 1995). Recently, several long (multi-year) time series have been collected, which permits the study of some minor deepocean constituents that are unrecoverable from altimetry given its inherently higher noise levels (Spencer and Vassie 1997, and see below).

The purpose of this paper is to exploit a unique BPR deployment in the South Atlantic: 12 recorders that were positioned in a straight line along a single ground track of the Topex/Poseidon and Jason series of satellites. Figure 1 shows the station locations. This deployment was part of the Agulhas South Atlantic Thermohaline Transport Experiment (Byrne and McClean 2008), designed to study the Indian-Atlantic interocean leakage associated with the 


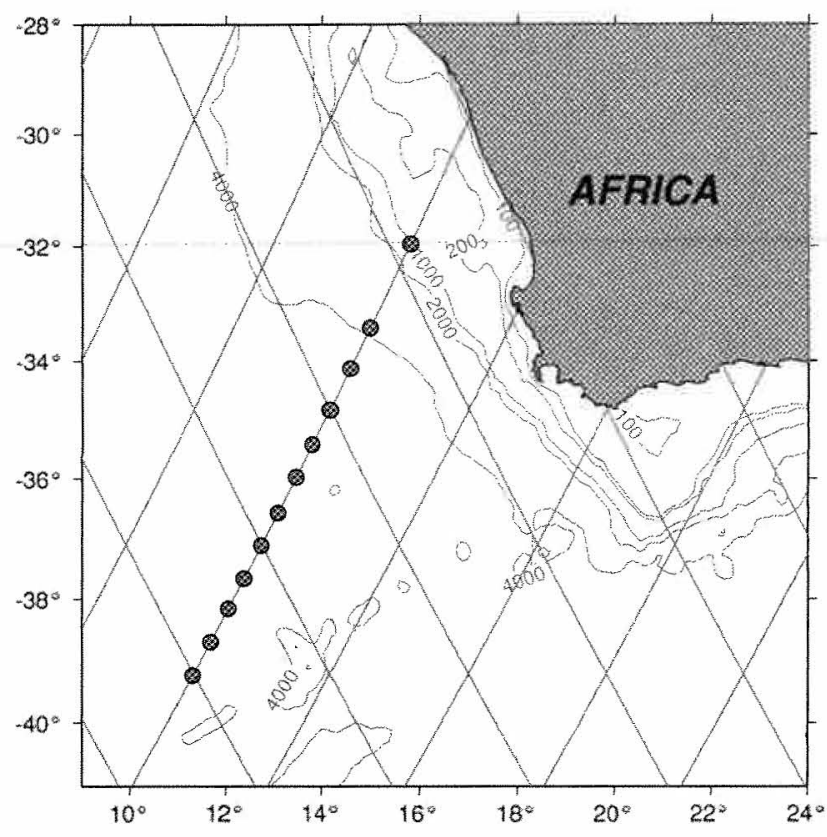

Fig. 1 Locations (small red circles) of the 12 bottom-pressure recorders used in this study. Pressure stations are numbered 1-12 from north to south; station 5 failed. Green lines mark the primary ground tracks of the Topex/Poseidon and Jason satellites; seasurface heights have been measured along these tracks every 9.916 days since September 1992. The pressure recorders are located on T/P pass \#133. Blue contour lines mark the 100-, 200-, $1,000-, 2,000-$, and 4,000-m isobaths

Agulhas Current. The along-track distance from northernmost to southernmost station is $904 \mathrm{~km}$. The line crosses a region of fairly intense mesoscale variability as is evident from satellite altimetry-see Fig. 2.

The deployment shown in Fig. 1 presents a unique opportunity for testing altimetric tide estimates in a way that randomly scattered stations cannot. Specifically, it allows us to explore how reliably tides can be estimated empirically from satellite altimeter data point by point along the satellite track in a region of high non-tidal variability.

The standard methods for determining tides from satellite altimetry generally analyze data simultaneously from multiple tracks (and sometimes multiple satellites) over regions extending over several hundred kilometers or more, often in conjunction with hydrodynamic assimilation techniques (e.g., Cartwright and Ray 1990; Egbert et al. 1994; Ma et al. 1994). Such methods, implicitly assuming a fairly long wavelength structure for the tidal wave being mapped, have successfully formed the basis for many of the tidal models now routinely used to remove tidal variability from altimetry (in addition to many other applications as well).

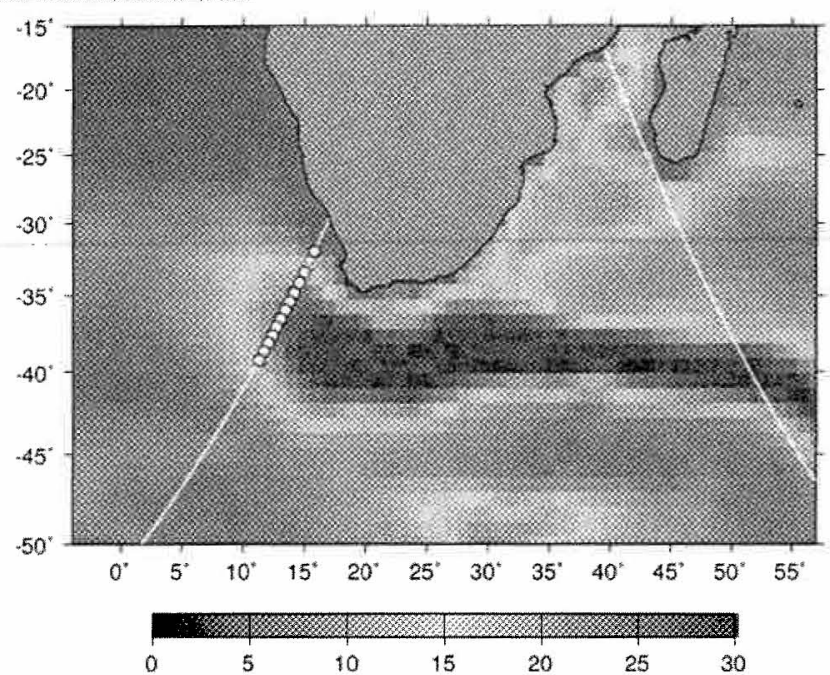

Fig. 2 Locations of the 12 bottom-pressure stations (small white circles) and satellite ground tracks (white lines) shown against a background of the rms sea-surface height variability (in centimeter), as computed from 15 years of Topex and Jason data. The eastern track is used in Section 5 and Fig. 6

In cases where very high spatial resolutions are required, along-track tidal analyses of satellite altimeter data can be attempted. Mapping the surface manifestation of open-ocean internal tides has been an especially fruitful use of along-track data (Ray and Mitchum 1996; Zhao and Alford 2009). Such analyses obviously require multiple years of exactly repeated tracks to ensure sufficient data to support a tidal inversion, so they began to appear only several years after the launch of T/P (Tierney et al. 1998; Carrère et al. 2004). Some progress concerning the reliability of along-track estimates has already been made. For example, Carrère et al. (2004) have examined the variance of alongtrack tide estimates from subset solutions and noted the generally inferior results obtained in regions of strong boundary currents-see especially their Fig. 5b (also Tierney et al. 1998, Fig. 12).

Our BPR array data allow direct tests of along-track tide estimates by comparing against very accurate and independent determinations. These tests are described in Sections 4 and 5. Before that, Section 2 describes the BPR data and the tidal estimates derived from them. The low noise levels in the BPR data and the linear station alignment also allow us to observe the amplitudes and phase propagation of some very small high-frequency tides rarely studied in the open ocean. As a prelude to the along-track comparisons, Section 3 compares the BPR tide estimates with some widely used global tidal models. Section 5 explores an approach to improve the along-track estimates in regions 
of high mesoscale variability, again using the BPR data as validation.

\section{Tides in ocean bottom pressure}

Time series of bottom pressure (BP) measurements at the stations shown in Fig. 1 span approximately 814 days, beginning in January 2003 and ending in March or April 2005. Station 3 has a short 18-day gap. At each site, six 1-min BP measurements were made per hour, at 10 -min intervals. The raw measurements were processed by despiking and averaging, resulting in hourly estimates of BP. The precision of the hourly BP measurements is approximately $0.2 \mathrm{mbar}$, based on instrument specifications from the manufacturer, Paroscientific, and on our own noise analysis. The instrumental sampling time was recorded immediately after deployment and immediately before recovery and clock drift estimated from this. If the measured clock drift was small ( 1 min per year or less), sampling is assumed to be at exactly $1-\mathrm{h}$ intervals, but the start and end times of the deployment were adjusted slightly. If the measured clock drift on recovery was large (more than 1 min per year) the recorded start and end times were used, a linear clock drift throughout the deployment is assumed, and the sampling interval was adjusted to something more or less than $10 \mathrm{~min}$. Clock drift was less than $1 \mathrm{~min}$ at station 8 , between 63 and $262 \mathrm{~s}$ at another eight moorings, and close to an hour at the remaining two moorings (stations 1 and 4).

The spectrum of one of our series (station 8) is shown in Fig. 3 (top). Typical of most sites, especially in the Atlantic Ocean, semidiurnal tides dominate. One is struck by the large number of isolated high-frequency $(\geq 3 \mathrm{cpd}$ ) lines clearly discernable in the spectrum, which is not typical of mid-ocean island tide gauges, but presumably owes to the low noise levels common to high-quality bottom pressure measurements (cf. Spencer and Vassie 1997). Moreover, the appearance of a series of prominent lines at integral multiples of one cycle per solar day, a characteristic of atmospheric tides, reminds us that bottom pressure includes the full signal of both oceanic and atmospheric tides, including the higher harmonics and seasonal modulations of the latter.

Spectra such as Fig. 3 were used as a guide for selecting which frequencies to include in our tidal analyses. For each station, we estimated between 72 and 90 tidal constituents. Amplitudes and phases were estimated by standard least-squares harmonic analysis with the usual allowance for nodal and perigee modulations of lunar tides. The only unusual aspect of this analysis, at least
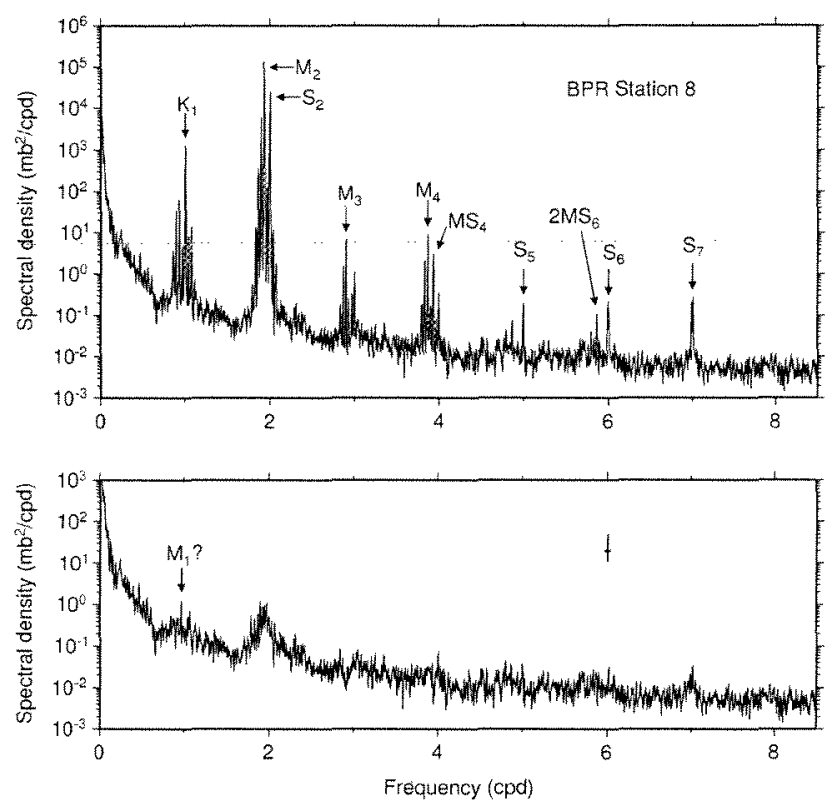

Fig. 3 Top Spectrum of the 814-day bottom pressure time series at station 8. Bottom Spectrum of the residual time series after removal of all estimated tides. Vertical line represents a $95 \%$ confidence interval, based on 14 degrees of freedom with frequency resolution approximately $0.005 \mathrm{cpd}$. Because of limited frequency resolution, some labels denote tidal groups (e.g., $\mathrm{S}_{6}$ ) in addition to constituents

for an open-ocean site, is the inclusion of a relatively large number of high-frequency lines. Although many of these lines are very small, they can be reliably determined owing to the low background noise levels.

Removal of the estimated tides from the pressure time series yields (for station 8) the spectrum shown in Fig. 3 (bottom). For the most part, isolated peaks in the original spectrum have been almost completely removed. A small one still noticeable in the diurnal band has a frequency of approximately $14.50^{\circ} \mathrm{h}^{-1}$ and is, we conjecture, caused by the degree- $3 \mathrm{M}_{1}$ tide which we cannot separate cleanly from the degree- $2 \mathrm{M}_{1}$ without the time series approaching 8 years in duration (Cartwright 1975). There is, in addition, a strong cusp of residual energy remaining across the semidiurnal band and a somewhat smaller cusp across the diurnal band. Although it is quite conspicuous, the semidiurnal cusp is five orders of magnitude smaller than the $\mathrm{M}_{2}$ line.

Space prevents a detailed tabulation of all tidal estimates, but Tables 1 and 2 present a subset representative of the overall quality of the estimates, including those for some very small lines (more complete tables of all computed tides are available from the authors upon request).

Table 1 lists the estimated tidal constants for the largest constituent within each tidal band, species 1 to 5 . 
Table 1 Selected estimated tidal constants $(H, G, \sigma)$ from bottom-pressure stations

\begin{tabular}{lllllll}
\hline Station & Location & $\mathrm{K}_{1}$ & $\mathrm{M}_{2}$ & $\mathrm{M}_{3}$ & $\mathrm{M}_{4}$ & $\mathrm{~S}_{5}$ \\
\hline 01 & $31.96^{\circ} \mathrm{S}, 15.81^{\circ} \mathrm{E}$ & $5.21,101.1^{\circ}, 0.08$ & $50.86,31.79^{\circ}, 0.13$ & $0.487,291^{\circ}, 0.022$ & $0.484,53^{\circ}, 0.024$ & $0.057,340^{\circ}, 0.021$ \\
02 & $33.42^{\circ} \mathrm{S}, 14.99^{\circ} \mathrm{E}$ & $5.01,105.1^{\circ}, 0.05$ & $50.78,32.58^{\circ}, 0.05$ & $0.457,294^{\circ}, 0.016$ & $0.452,46^{\circ}, 0.013$ & $0.046,338^{\circ}, 0.011$ \\
03 & $34.12^{\circ} \mathrm{S}, 14.58^{\circ} \mathrm{E}$ & $4.86,107.4^{\circ}, 0.05$ & $50.49,32.85^{\circ}, 0.07$ & $0.452,294^{\circ}, 0.016$ & $0.445,44^{\circ}, 0.014$ & $0.052,338^{\circ}, 0.010$ \\
04 & $34.83^{\circ} \mathrm{S}, 14.16^{\circ} \mathrm{E}$ & $4.70,109.1^{\circ}, 0.06$ & $50.53,32.87^{\circ}, 0.06$ & $0.418,295^{\circ}, 0.016$ & $0.432,41^{\circ}, 0.011$ & $0.052,338^{\circ}, 0.010$ \\
05 & $35.43^{\circ} \mathrm{S}, 13.80^{\circ} \mathrm{E}$ & & & & & \\
06 & $35.97^{\circ} \mathrm{S}, 13.47^{\circ} \mathrm{E}$ & $4.40,111.3^{\circ}, 0.05$ & $49.33,33.28^{\circ}, 0.05$ & $0.383,295^{\circ}, 0.012$ & $0.420,35^{\circ}, 0.014$ & $0.050,340^{\circ}, 0.008$ \\
07 & $36.57^{\circ} \mathrm{S}, 13.09^{\circ} \mathrm{E}$ & $4.24,112.4^{\circ}, 0.05$ & $49.08,33.50^{\circ}, 0.07$ & $0.378,297^{\circ}, 0.013$ & $0.421,33^{\circ}, 0.015$ & $0.042,336^{\circ}, 0.007$ \\
08 & $37.12^{\circ} \mathrm{S}, 12.74^{\circ} \mathrm{E}$ & $4.12,113.1^{\circ}, 0.05$ & $48.47,33.24^{\circ}, 0.05$ & $0.341,298^{\circ}, 0.009$ & $0.409,29^{\circ}, 0.014$ & $0.042,331^{\circ}, 0.007$ \\
09 & $37.66^{\circ} \mathrm{S}, 12.38^{\circ} \mathrm{E}$ & $3.95,114.9^{\circ}, 0.05$ & $47.71,33.35^{\circ}, 0.06$ & $0.332,298^{\circ}, 0.010$ & $0.396,25^{\circ}, 0.012$ & $0.039,332^{\circ}, 0.006$ \\
10 & $38.16^{\circ} \mathrm{S}, 12.06^{\circ} \mathrm{E}$ & $3.80,114.2^{\circ}, 0.05$ & $47.27,33.28^{\circ}, 0.06$ & $0.318,298^{\circ}, 0.013$ & $0.397,22^{\circ}, 0.014$ & $0.046,327^{\circ}, 0.006$ \\
11 & $38.70^{\circ} \mathrm{S}, 11.69^{\circ} \mathrm{E}$ & $3.63,114.8^{\circ}, 0.05$ & $46.54,33.08^{\circ}, 0.06$ & $0.295,298^{\circ}, 0.013$ & $0.389,19^{\circ}, 0.014$ & $0.037,326^{\circ}, 0.006$ \\
12 & $39.24^{\circ} \mathrm{S}, 11.31^{\circ} \mathrm{E}$ & $3.47,115.3^{\circ}, 0.04$ & $45.98,33.08^{\circ}, 0.06$ & $0.263,299^{\circ}, 0.012$ & $0.392,13^{\circ}, 0.013$ & $0.039,324^{\circ}, 0.006$ \\
\hline
\end{tabular}

Amplitudes $H$ in millibar; Greenwich phase lags $G$ in degrees; standard errors $\sigma$ in millibar. The standard error in phase is given approximately by $\sigma / H$ in radians, unless $H$ is small, in which case more accurate formulae are available in Appendix B of Munk and Cartwright (1966)

Table 1 does not include species 0 (i.e., the long-period tides) because they appear too unreliable, with uncertainties comparable to amplitudes; reliable estimates of long-period tides generally require many years of data in part because of increasing background noise levels at lower frequencies.

Standard errors were estimated in two ways: from the standard deviation of monthly (subset) estimates scaled by $k^{-1 / 2}$ for $k$ months of the entire time series and from the diagonal of the (unweighted) least squares covariance matrix scaled by the spectral noise background near each tidal line. These two error estimates were found to be generally comparable but would occasionally differ as much as $\sim 2: 1$. To be conservative, we here adopt the second error but augmented by a factor of 2. These standard errors are also listed in Table 1. Note the general reduction in uncertainties for the higher frequency tides.

Table 2 Estimated amplitudes (millibar) and phase lags (degrees) for $\mathrm{S} 6$ and its seasonal sidelines

\begin{tabular}{lllll}
\hline Station & $2 \mathrm{~T}_{6}$ & $\mathrm{~T}_{6}$ & $\mathrm{~S}_{6}$ & $2 \mathrm{R}_{6}$ \\
\hline 01 & $0.071,175^{\circ}$ & $0.006,242^{\circ}$ & $0.047,177^{\circ}$ & $0.055,122^{\circ}$ \\
02 & $0.072,188^{\circ}$ & $0.012,265^{\circ}$ & $0.038,182^{\circ}$ & $0.058,144^{\circ}$ \\
03 & $0.067,191^{\circ}$ & $0.018,299^{\circ}$ & $0.038,199^{\circ}$ & $0.060,138^{\circ}$ \\
04 & $0.066,187^{\circ}$ & $0.015,305^{\circ}$ & $0.033,189^{\circ}$ & $0.053,142^{\circ}$ \\
06 & $0.059,192^{\circ}$ & $0.016,325^{\circ}$ & $0.034,192^{\circ}$ & $0.047,142^{\circ}$ \\
07 & $0.061,186^{\circ}$ & $0.015,330^{\circ}$ & $0.030,188^{\circ}$ & $0.044,143^{\circ}$ \\
08 & $0.058,191^{\circ}$ & $0.012,313^{\circ}$ & $0.032,186^{\circ}$ & $0.048,143^{\circ}$ \\
09 & $0.051,188^{\circ}$ & $0.011,337^{\circ}$ & $0.027,191^{\circ}$ & $0.046,143^{\circ}$ \\
10 & $0.049,193^{\circ}$ & $0.008,320^{\circ}$ & $0.026,185^{\circ}$ & $0.044,144^{\circ}$ \\
11 & $0.050,189^{\circ}$ & $0.012,354^{\circ}$ & $0.030,186^{\circ}$ & $0.045,142^{\circ}$ \\
12 & $0.042,193^{\circ}$ & $0.016,357^{\circ}$ & $0.022,189^{\circ}$ & $0.040,144^{\circ}$ \\
\hline
\end{tabular}

Standard errors for all four tides are approximately $0.004 \mathrm{mbar}$, except 0.006 mbar for station 1
Note also the considerably larger uncertainties at station 1. The spectrum for station 1 (not shown) reveals a significantly enhanced background noise level at all frequencies $\geq 1 \mathrm{cpd}$. It also reveals an intriguing mound of non-tidal energy centered near frequency $1.3 \mathrm{cpd}$. This is in contrast to the relatively low mesoscale variability at station 1 as determined from satellite altimetry and depicted in Fig. 2.

As is evident from Table 1, the diurnal tides in this region of the Atlantic are fairly small, $5 \mathrm{~cm}$ or less, with $\mathrm{K}_{1}$ amplitudes roughly an order of magnitude smaller than $\mathrm{M}_{2}$. As expected, the terdiurnal $\mathrm{M}_{3}$ and quarterdiurnal $\mathrm{M}_{4}$ are small, between 3 and $5 \mathrm{~mm}$, but are very reliably estimated owing to the low BPR noise levels in these frequency bands. $M_{3}$ is undoubtedly the linear wave generated by the third-degree term in the moon's astronomical potential. As such, its phases are fairly constant across all stations, suggestive of broad wavelengths somewhat comparable to the diurnal and semidiurnal waves. Its amplitude, however, is decaying rapidly away from the coast of Africa. Cartwright et al. (1980) produced a cotidal chart for the northeast Atlantic Ocean based on their dense array of BPR stations, but we know of no regional chart for the southeast Atlantic, nor of any global models of $\mathrm{M}_{3}$, numerical or otherwise. So we cannot at this stage place our estimates in a wider context. We note, nonetheless, that the $\mathrm{M}_{3}$ chart of Cartwright et al. does show a rapid decay in amplitude off the coasts of Ireland and France, with fairly constant phases. Farther to sea, two amphidromes could be mapped where none exist for diurnal or semidiurnal waves, thus emphasizing the spatial complexity of the terdiurnal wave.

In contrast to the linear $\mathrm{M}_{3}$, the $\mathrm{M}_{4}$ constituent is the nonlinear overtide of $\mathrm{M}_{2}$ and probably represents a 
freely propagating wave that is generated elsewhere in shallow water. Interestingly, the phase lags in Table 1 indicate wave propagation toward Africa, so the $\mathrm{M}_{4}$ source region is certainly not evident from our BPR data. Recently, the $\mathrm{M}_{4}$ tide has been coarsely mapped over most of the Atlantic Ocean by satellite altimetry. Comparisons between our estimates and the altimetric cotidal chart (Ray 2007, Fig. 1) show reasonably good agreement, especially for the southernmost stations away from the African continent. The broader context afforded by the altimetry suggests that $\mathrm{M}_{4}$ in this region is part of an amphidromic system forced by waves originating along the southern African coast and on the Patagonian Shelf.

The fifth-diurnal $S_{5}$, equivalent to a wave of only half a millimeter in sea-surface height, emphasizes the power of bottom-pressure measurements to extract such tiny signals-compare, for example, the $S_{5}$ peak in Fig. 3 with the much larger terdiurnal and quarterdiurnal peaks. Nonetheless, $S_{5}$ stands out clearly above background. Similar to results shown by Cartwright et al. (1988) and Spencer and Vassie (1997), $S_{5}$ is one of a series of peaks seen at integral multiples of exactly one cycle per solar day. Such lines are characteristic of the spectrum of atmospheric surface pressure (e.g., Smylie et al. 1993) and represent higher harmonics of the atmospheric tide. Thus, $S_{S}$ in Table 1 , as well as the other $S_{n}(n \neq 2)$ lines evident in the BPR spectrum, are likely the combined result of the atmosphere's $S_{n}$ barometric tide and the ocean's (dynamic) response to that load. One note of caution concerning this interpretation stems from an (unpublished) analysis of the atmospheric tides at St. Helena $\left(16^{\circ} \mathrm{S}, 6^{\circ} \mathrm{W}\right)$ which finds an $S_{5}$ amplitude of $8 \mu \mathrm{bar}$, several times smaller than the amplitudes in Table 1. However, the seasonal sidelines in St. Helena air pressure, occurring at frequencies $\mathrm{S}_{5} \pm 1 \mathrm{cpy}$, are larger -14 and $15 \mu \mathrm{bar}$ - which is not the case in our BPR data, so the air tide at St. Helena, some $3,000 \mathrm{~km}$ distant, may be a poor proxy for the tide at our array in the South Atlantic.

Finally, Table 2 tabulates four constituents within the sixth-diurnal band, specifically $S_{6}$ and its annual and semi-annual sidelines. The nomenclature adopted here for the sidelines is nonconventional, but it mimics Kelvin's nomenclature for the annual sidelines of $S_{2}$. Specifically, the frequencies of the four lines are:

$\begin{array}{ll}2 \mathrm{~T}_{6}: & 6 \mathrm{cpd}-2 \mathrm{cpy} \\ \mathrm{T}_{6}: & 6 \mathrm{cpd}-1 \mathrm{cpy} \\ \mathrm{S}_{6}: & 6 \mathrm{cpd} \\ 2 \mathrm{R}_{6}: & 6 \mathrm{cpd}+2 \mathrm{cpy}\end{array}$

An $R_{6}$ constituent was also estimated but was found to be much smaller than these other lines and is not shown. Standard errors for all four constituents are approximately 0.004 mbar (slightly larger for station 1 ). As the data in Table 2 show, these very small amplitude signals appear to be reliably estimated from the BPR data, with good consistency from station to station. Most of the constituents show fairly constant phase across all stations, as one would expect if forcing is from a relatively low-wavenumber air tide. Interestingly, the two semi-annual sidelines are much larger than the annual sidelines and even larger than the central $S_{6}$ line. There appears to be phase propagation in the small $\mathrm{T}_{6}$, although its phases are somewhat erratic, which is to be expected-the standard errors in the $T_{6}$ phases are $\sim(0.004 / 0.012) \mathrm{rad}$, or about $20^{\circ}$ (note that in Fig. 3, these sixth-diurnal constituents merge into a single isolated peak owing to the band-averaging used to compute the spectrum).

\section{Comparisons with global models}

This section compares our tidal constants extracted from the BPR data with the corresponding constants of some widely used global tidal models. It is of interest to make such comparisons as a straightforward check on the models, but one should not read too much into the results. Serious tests of global models require much more extensive comparisons, of the sort performed by Shum et al. (1997; although the models examined by Shum et al. are now admittedly obsolete).

We examine three recent global models: FES2004 from Lyard et al. (2006), TPXO7.1 which is an update of work done by Egbert and Erofeeva (2002), and GOT4.7 which is an update to work done by the senior author (Ray 1999). The methodologies behind these models are quite different as are the data employed in producing them. FES and TPXO both use representer-type inverse methodologies with linearized hydrodynamics models. In the region of interest here, it is safe to assume that all three are constrained by altimeter data from the Topex/Poseidon and Jason-1 satellites, although possibly downweighted somewhat in the regions of high mesoscale variability. FES is also fitted to ERS altimetry and tide gauge data along the coast of Africa-see Fig. 3 of Lyard et al. (2006).

The main comparison results for these models are shown in Fig. 4, where the model amplitudes and phases have been evaluated along the satellite ground track and plotted as a function of latitude. Given the very small amplitudes of the diurnal tides in this region (see Table 1), we focus on the three largest semidiurnal tides: $\mathrm{M}_{2}, \mathrm{~S}_{2}$, and $\mathrm{N}_{2}$. The BPR station data, shown as circles in Fig. 4, are seen to agree well with the models, 


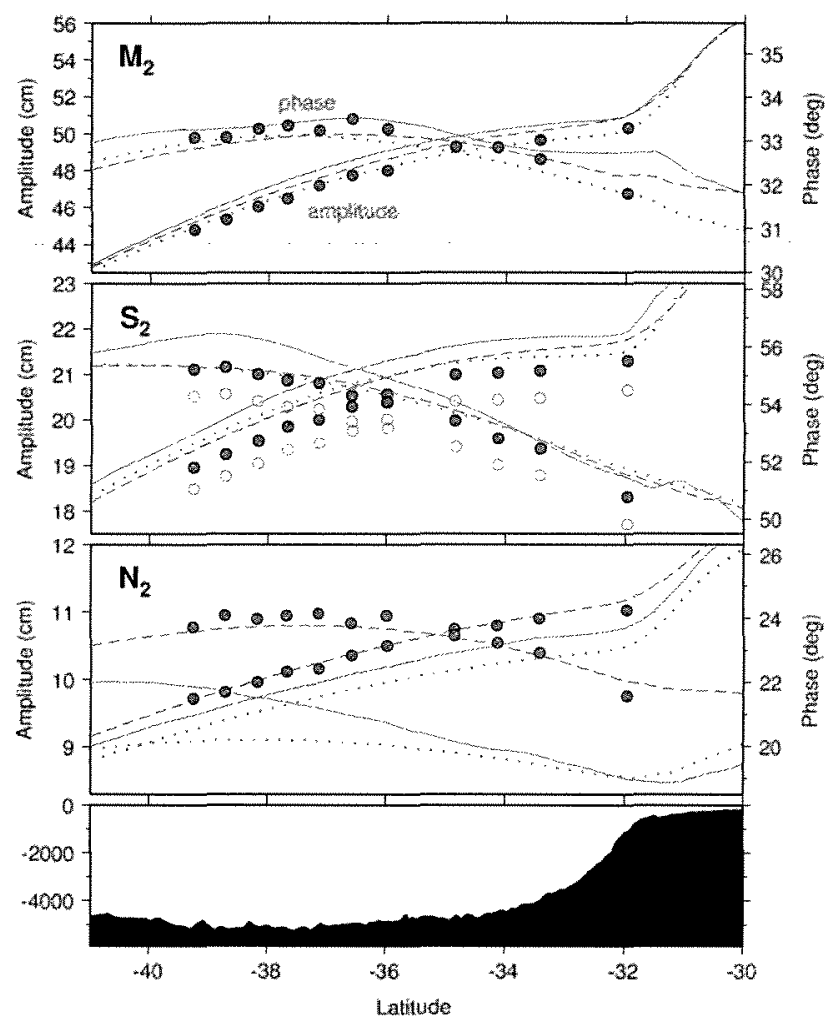

Fig. 4 Comparisons of the amplitudes (in red) and phase lags (in blue) of the three largest constituents in 11 bottom-pressure stations against amplitudes and phases from three global tidal models: GOT4.7 (solid line), TPXO7.1 (dashed line), and FES2004 (dotted line). The model fields are extracted by bilinear interpolation at the positions of the satellite ground track shown in Fig. I. The BPR constants are given by filled circles; the unfilled circles for $S_{2}$ are before correcting the data for the $S_{2}$ air tide. Standard errors for the BPR data are, with some exceptions, the size of the shown circles or smaller. Bathymetry profile along the satellite ground track is shown at bottom

except perhaps for the $\mathrm{N}_{2}$ phases of FES and GOT which appear offset by about $4^{\circ}$. Note, however, that for such a small amplitude $(\sim 10 \mathrm{~cm})$, a $4^{\circ}$ error in phase induces a prediction error still well below $1 \mathrm{~cm}$ absolute.

For these comparisons, the $S_{2}$ constituent warrants special attention since the original estimates from the BPR data include the signal from the $S_{2}$ atmospheric tide. To remove that signal, we here employ the analytical model of Haurwitz and Cowley (1973):

$P(\theta, \phi, t)=1161 \sin ^{3} \theta \sin \left(2 t+2 \phi+159^{\circ}\right) \mu \mathrm{bar}$

where $(\theta, \phi)$ are standard polar coordinates and $t$ is Universal Time. In the vicinity of our stations, this analytical model implies an $S_{2}$ air-tide amplitude and phase lag of 0.64 mbar and $271^{\circ}$, respectively. It is clear from Fig. 4 that correcting for the air tide improves the agreement between models and BPR data in both amplitude and phase. Nonetheless, all three model amplitudes of $S_{2}$ still exceed the BPR amplitudes at all stations (more so for GOT) by 5 to $10 \mathrm{~mm}$. One wonders if the simple Haurwitz-Cowley model is not sufficiently accurate, but evaluation of the $S_{2}$ air tide implied by the operational model of the European Centre for Medium-range Weather Forecasting (ECMWF; Ray and Ponte 2003) gives an amplitude and phase of 0.51 mbar and $273^{\circ}$, respectively, which is close to the analytical model.

The reader should not be misled by the modelBPR discrepancies seen in the rather magnified view of Fig. 4. In fact, the rms differences between the BPR data and all three models are well under $1 \mathrm{~cm}$ for each of the constituents. In terms of full tidal height prediction, the rms difference between GOT4.7 heights and predicted heights based on our estimated tidal constants for station 9 (for example) is $2.4 \mathrm{~cm}$. Some of this difference, approximately $0.4 \mathrm{~cm}$, represents errors of omission in GOT4.7 since that model includes no high-frequency constituents except $\mathrm{M}_{4}$.

\section{Comparisons with along-track altimetry}

As noted in the Section 1, a more opportune use of our BPR array is to test the results of along-track analyses of altimeter data. For this work, we use 597 repeat cycles (354 from T/P, 243 from Jason-1) of sea-surface heights collected over 17 years along the ground track shown in Fig. 1. Our datasets from the two different altimeters have been carefully merged for consistency, with customized orbits computed in a consistent terrestrial reference frame and satellite range and radiometer biases calibrated against independent data; for details, see Beckley et al. (2004).

We applied mostly standard corrections to the data with a few exceptions. For example, our correction for atmospheric loading is based on an isostatic response to ECMWF air pressures but only after averaging to form daily means; this (a) acknowledges the ocean's nonisostatic response at sub-daily frequencies, for which no correction at all is preferable to an invalid inverted barometer, and (b) avoids corrupting our tidal estimates with an invalid correction that contains air-tide signals. Obviously, we do not apply an ocean-tide correction, but we do apply corrections for the body tide (based on a strictly elastic response to the astronomical potential) and for the load tide (based on the global model GOT4.7). The latter has an $\mathrm{M}_{2}$ amplitude in this part of the Atlantic of about $3 \mathrm{~cm}$ (Ray 1999, Fig. B1); diurnal load tides have amplitudes less than $3 \mathrm{~mm}$ here.

We use a response tidal analysis (Cartwright and Ray 1990), although a harmonic analysis gives very 
similar results for the major tides (Tierney et al. 1998). The analysis is applied to data every $5.8 \mathrm{~km}$ along the satellite ground track, with neighboring locations treated completely independently. At each location, the maximum possible length of the analyzed time series is 597 , but owing to data gaps or outlier edits, the median length of each series is in actuality 544 . Results for the $\mathrm{M}_{2}, \mathrm{~S}_{2}$, and $\mathrm{N}_{2}$ constituents are shown, along with the BPR-based values, in Fig. 5. The agreement between altimeter and BPR-based tides is not especially impressive. This is consistent with results found by Tierney et al. (1998) and others in high-variability regions of the ocean, even though earlier studies had less (sometimes much less) data than we do. Note that the discrepancies between BPR and altimeter estimates in Fig. 5 are generally within one standard error, which indicates that these error bars are indeed reliable and provide a useful guide in regions without independent measurements. Note too that the error bars are much smaller at station 1 and northwards, which is consistent with the background variability depicted in Fig. 2 .

The rms discrepancy between the BPR and altimeter-based tides of Fig. 5, after applying a

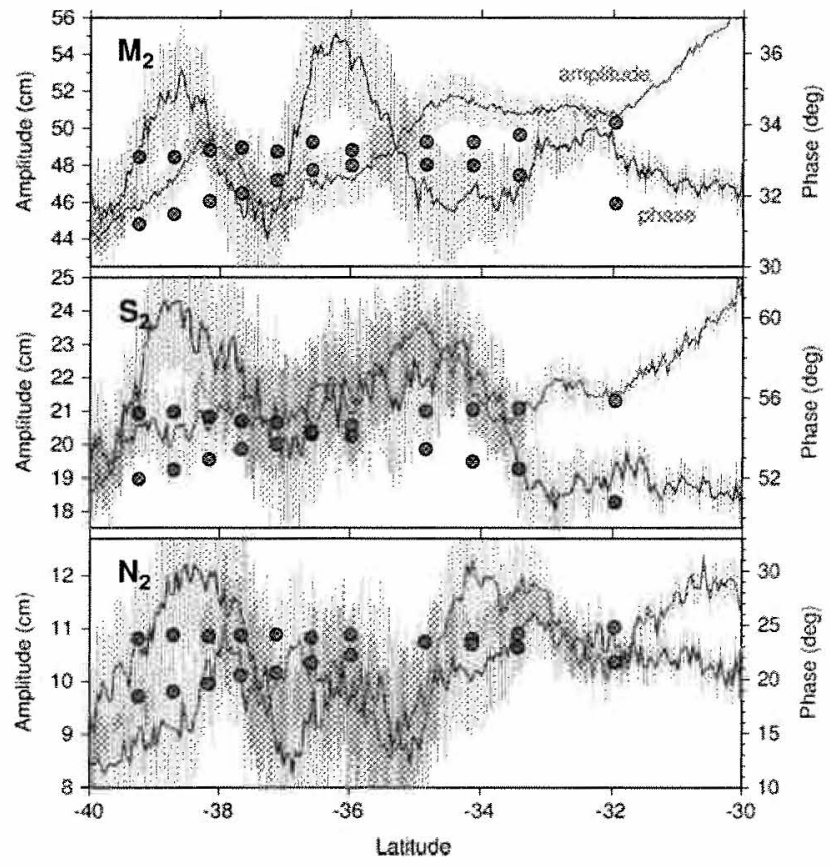

Fig. 5 Along-track estimates of the amplitudes (solid red curves) and phase lags (solid blue curves) of three largest semidiurnal tides, derived from 597 cycles of Topex/Poseidon and Jason1 altimetry along the ground track shown in Fig. 1 . Standard errors are shown as vertical lines in fainter colors. Circles mark amplitudes and phases lags derived by our 11 bottom-pressure stations five-point running average to dampen some of the point-to-point noise in the altimeter data, is $2.0 \mathrm{~cm}$ for $\mathrm{M}_{2}$ and $1.6 \mathrm{~cm}$ for $\mathrm{S}_{2}$. For some purposes, such errors may be acceptable, but for more demanding applications (e.g., the study of internal tides whose surface amplitudes are often sub-centimeters), they are not acceptable.

\section{Improvement of along-track tides}

Can the along-track altimeter estimates be improved? The primary problem seems to occur in regions where mesoscale variability exceeds an rms level of $15-20 \mathrm{~cm}$. It is understandable that tidal estimates based on only $\sim 600$ sea-level measurements will be severely impacted by such high noise levels. Desai et al. (1997) noted similar problems in their tidal analyses. Tierney et al. (1998) rightly noted that a longer altimetric time series can mitigate background noise, but our Topex-Jason time series is now 17 years and our patience is limited.

An obvious route to improvement is to remove the non-tidal ocean variability via a prior model. It is unlikely that any model could be sufficiently accurate unless it itself is based on altimetry. We have found some success by adopting the purely empirical seasurface anomaly fields produced by the Archiving, Validation and Interpretation of Satellite Oceanographic data (AVISO) project at Centre National d'Etudes Spatiales (CNES) and Collecte Localisation Satellites. We use the multi-mission 1/4-degree global grids produced weekly from the altimetry using some combination of the satellites Topex, Jason-1, GFO, Envisat, ERS-1, and ERS-2 (Le Traon et al. 1998; Ducet et al. 2000; Pascual et al. 2006). During some periods, as many as four simultaneously flying altimetric satellites contribute to the anomaly fields.

We apply the AVISO fields as a prior correction before subjecting the altimetry to tidal analysis. Obviously, great caution is warranted at this step. It is possible that tide modeling errors committed by AVISO could be absorbed into their anomaly fields; using such fields as a correction term would cause our subsequent tidal analysis simply to recover AVISO's adopted tide model. This is especially critical for internal-tide signals (which appear as short-wavelength tide errors to AVISO) since those short scales would seem to be most easily accommodated by AVISO's interpolator, the internal tides possibly appearing as false eddy-like features. We have discovered that this can happen on occasion, but in general, AVISO's use of multiple satellites with differing sampling patterns and aliasing periods appears to prevent most of their 
tide-model errors from contaminating their resulting anomaly fields. We surmise that in this regard the more altimeters flying the better, and any period in which only one or two altimeters are operational may be more problematic.

As a test example of applying this technique, consider the eastern track shown in Fig. 2, which spans a region with both internal tides and high mesoscale variability (although not in the same locations). The track crosses the Mozambique Channel between the African continent and Madagascar, then proceeds into the southwest Indian Ocean where it crosses the Antarctic Circumpolar Current. Figure 6 shows the results of a tidal analysis of 597 cycles of altimeter data for this track, with the amplitudes high-pass filtered to highlight internal-tide signals (in the manner of Ray and Mitchum (1996)). The waves north of $30^{\circ} \mathrm{S}$ are the surface manifestation of internal tides. The phases (not shown) indicate northward propagation along the track, probably from a source somewhere along the Madagascar Ridge. The results of the standard analysis (top diagram) show similarly sized oscillations, although of a clearly different character, to the south in the vicinity of the ACC. These are similar to the alongtrack errors seen in Fig. 5. After applying the AVISO anomaly data as a prior correction (bottom diagram), the large offsets around the ACC are much reduced. Yet the internal-tide signals are mostly unaffected; only a slight reduction in amplitude is noticeable for the anomalies around $28-29^{\circ} \mathrm{S}$, while the phases (not
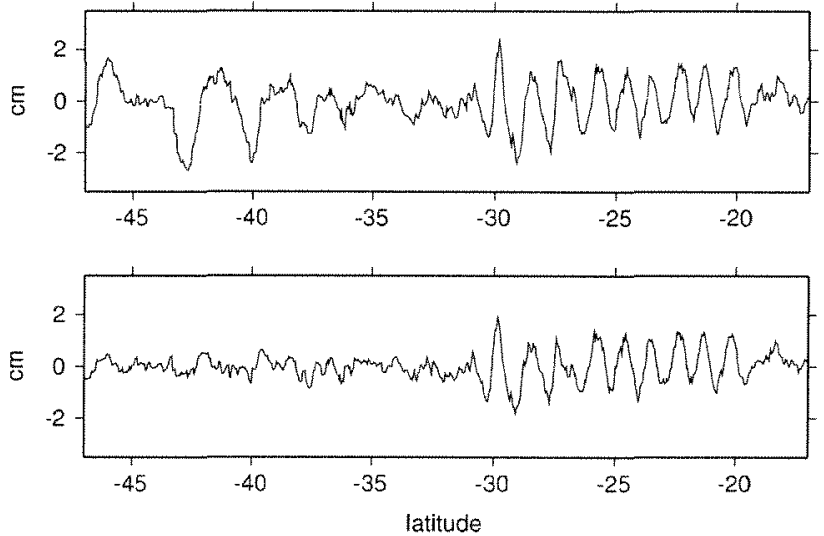

Fig. 6 High-pass filtered $M_{2}$ amplitude estimates along pass $\# 120$, shown in Fig. 2 east of Africa, based on tidal analysis of 597 cycles of Topex/Poseidon and Jason-1 altimetry, without (top) and with (bottom) having first corrected the data for nontidal ocean variability. The oscillations north of $30^{\circ} \mathrm{S}$ are induced primarily by internal tides (cf. Ray and Mitchum 1996), and these signals are for the most part unaffected by the correction for nontidal variability shown) are hardly affected at all. We conclude that, for the most part, the AVISO-based corrections to the altimetry successfully remove a significant portion of non-tidal ocean variability but leave the sought-after tidal signals mostly intact.

Returning now to our original track in the southeast Atlantic, we apply the same technique. Figure 7 shows tidal estimates obtained after applying the AVISObased correction. The agreement between the altimeter tide estimates and the BPR tide estimates is clearly improved relative to those in Fig. 5. There is still an odd increase in $S_{2}$ amplitude around latitude $35^{\circ} \mathrm{S}$ and a noticeable discrepancy in $M_{2}$ phase for station 1. It also appears that the discrepancies between altimetry and BPR estimates for both $\mathrm{M}_{2}$ and $\mathrm{S}_{2}$ are very close to or exceed the $1-\sigma$ standard error range for most of the stations, which suggests that the error bars may now be slightly too small, although $\mathrm{N}_{2}$ error bars appear realistic. Overall, the improvement in Fig. 7 for all three constituents is very good.

Quantitative assessments of the improvement are given in Table 3. Also shown in Table 3 are similar results based on using only 110 cycles of the altimetry, rather than the full 597 cycles; 110 cycles correspond to about 3 years of data, or a typical satellite mission lifetime. This allows us to judge the relative efficacies of the AVISO ocean correction versus more data.

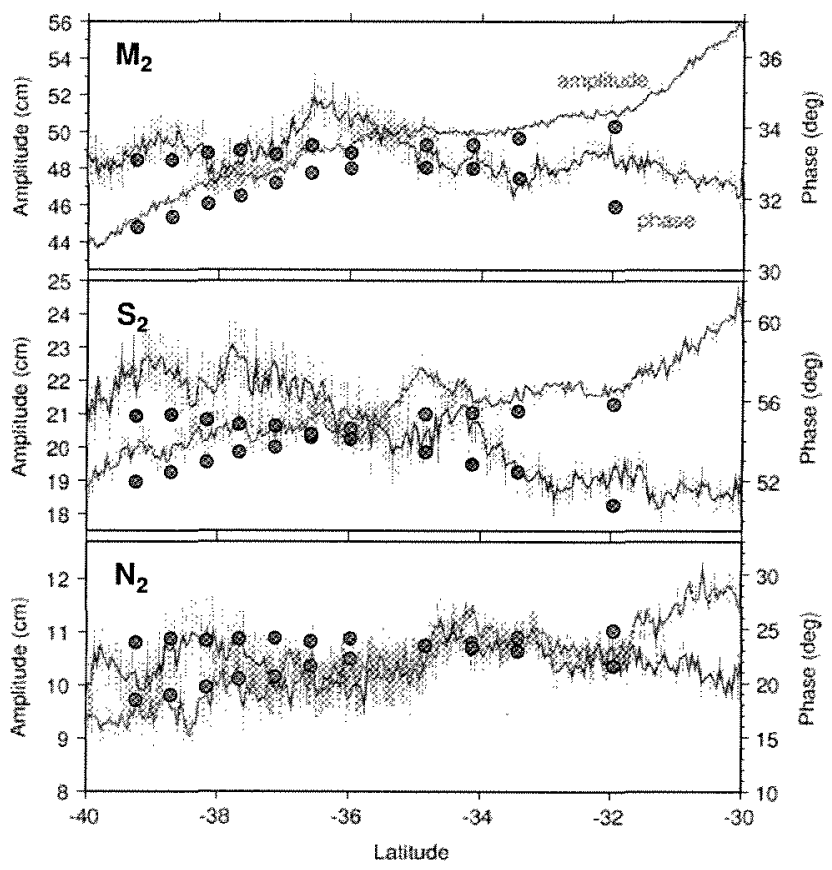

Fig. 7 As in Fig. 5, but with the along-track data having first been corrected for non-tidal ocean variability 
Table 3 RMS differences (centimeter) between BPR tides and various along-track altimeter estimates

\begin{tabular}{lllllll}
\hline $\begin{array}{l}\text { Number } \\
\text { of cycles }\end{array}$ & $\begin{array}{l}\text { Ocean } \\
\text { correction? }\end{array}$ & $\mathrm{M}_{2}$ & $\mathrm{~S}_{2}$ & $\mathrm{~N}_{2}$ & $\mathrm{~K}_{1}$ & $\mathrm{O}_{1}$ \\
\hline 110 & No & 4.87 & 4.57 & 2.55 & 7.18 & 3.77 \\
110 & Yes & 3.73 & 1.61 & 0.94 & 1.31 & 1.93 \\
597 & No & 1.98 & 1.55 & 1.15 & 3.81 & 0.92 \\
597 & Yes & 1.11 & 1.00 & 0.53 & 0.93 & 0.66 \\
\hline
\end{tabular}

Obviously, both are beneficial. More data seem to benefit $\mathrm{M}_{2}$ more noticeably; the ocean correction seems to benefit $K_{1}$. In fact, the $K_{1}$ errors without the ocean correction are unacceptably large. This probably stems from the fact that $K_{1}$ has the longest alias period of the four tabulated tides, so it is more sensitive to lowfrequency variability. Moreover, that alias is 173 days, so it is especially contaminated by the semi-annual cycle in sea level. The ocean correction is seen to mitigate this contamination effectively.

With the improved altimetric tide estimates shown in Fig. 7, unlike the originals in Fig. 5, we can now state that there is little evidence along this track for the existence of significant phase-locked internal tides, of the sort seen above in Fig. 6. In this region of the Atlantic, mode- 1 semidiurnal internal tides would have an expected wavelength of around $150 \mathrm{~km}$. In addition to their tell-tale wiggles (as in Fig. 6), such tides would induce an additional along-track discrepancy between the altimetric and BPR data. If they do exist in this region, their surface manifestations are very small, well less than $1 \mathrm{~cm}$.

\section{Summary}

Long time series of deep-ocean bottom-pressure recorders located in relatively close proximity are invaluable in their own right for the new information they reveal about tides, especially small constituents that are otherwise undetectable in noisy surface measurements. Tables 1 and 2 give examples of such small constituents, with their phase propagation directions and speeds readily apparent across the array. Future planned studies with complementary data-for example, with inverted echo sounders, which were colocated with the BPRs-should add to the utility of these data. But the array here, aligned along the primary $\mathrm{T} / \mathrm{P}$ Jason satellite ground track, is unique for giving us an independent dataset for testing analyses of satellite altimeter data. Along-track tidal analysis of altimetry is an invaluable tool for exploring short-scale tidal features in the ocean (e.g., Zhao and Alford 2009), but the tidal estimates tend to be corrupted in regions of moderately high mesoscale variability. The location of our track in such a region (Fig. 2) adds further to its utility as a testbed for the analysis of altimeter data.

Section 5 introduces a procedure that appears to reduce substantially the contamination of along-track tide estimates by non-tidal variability. The use of the $1 / 4$ degree sea-surface height product created by AVISO as a "correction" for non-tidal variability could be problematic if it contained within it false anomalies induced by errors in AVISO's adopted tide model. This appears not to occur-at least not here, nor in other regions we have examined, although we have found a few isolated exceptions (e.g., near the Florida Straits). Almost certainly the success relies on AVISO having at least two, usually three, and sometimes four, concurrently operating satellite altimeters to map global sea-surface heights. These multiple satellites typically have different tidal alias periods and sample tides at different phases, and this evidently (and fortunately) makes AVISO's interpolator less likely to absorb tidal errors into their mapped product. We anticipate our altimeter correction procedure to be useful for studying the small internal-tide signals which are detectable across large stretches of the global ocean.

Acknowledgements Brian Beckley is thanked for his help in processing Topex/Poseidon and Jason-1 altimeter data. Those data were obtained as Geophysical Data Records from PODAAC, Jet Propulsion Laboratory, Pasadena. The altimeterbased sea-level anomaly grids used here as a correction were produced by SSALTO/DUACS and distributed by AVISO with support from CNES. This work was supported by the Ocean Surface Topography program of the US National Aeronautics and Space Administration and by grant OCE-0099177 from the National Science Foundation.

\section{References}

Beckley BD, Zelensky NP, Luthcke SB, Callahan PS (2004) Towards a seamless transition from Topex/Poseidon to Jason-1. Marine Geod 27:373-389

Byrne DA, McClean JL (2008) Sea level anomaly signals in the Agulhas Current. Geophys Res Lett 35:L13601

Carrère L, Le Provost C, Lyard F (2004) On the statistical stability of the $\mathrm{M}_{2}$ barotropic and baroclinic tidal characteristics from along-track Topex/Poseidon satellite altimetry analysis. J Geophys Res 109:C03033

Cartwright DE (1975) A subharmonic lunar tide in the seas off western Europe. Nature 257:277-280

Cartwright DE, Ray RD (1990) Oceanic tides from Geosat altimetry. J Geophys Res 95:3069-3090

Cartwright DE, Edden AC, Spencer R. Vassie JM (1980) The tides of the Northeast Atlantic Ocean. Philos Trans R Soc Lond Ser A 298:88-139 
Cartwright DE, Spencer R, Vassie JM, Woodworth PL (1988) The tides of the Atlantic Ocean, $60^{\circ} \mathrm{N}$ to $30^{\circ} \mathrm{S}$. Philos Trans R Soc Lond Ser A 324:513-563

Desai SD, Wahr JM, Chao Y (1997) Error analysis of empirical ocean tide models estimated from Topex/Poseidon altimetry. J Geophys Res 102:25157-25172

Ducet, N, Le Traon P-Y, Reverdin G (2000) Global high resolution mapping of ocean circulation from Topex/Poseidon and ERS-1 and -2. J Geophys Res 105:19477-19498

Egbert GD, Erofeeva SY (2002) Efficient inverse modeling of barotropic ocean tides. J Atmos Ocean Technol 19:183-204

Egbert GD, Bennett AF, Foreman MGG (1994) Topex/Poseidon tides estimated using a global inverse model. J Geophys Res 99:24821-24852

Haurwitz B, Cowley AD (1973) The diurnal and semidiurnal barometric oscillations, global distribution and annual variation. Pure Appl Geophys 102:193-222

Le Traon, P-Y, Nadal F, Ducet N (1998) An improved mapping method of multisatellite altimeter data. J Atmos Ocean Technol 15:522-534

Lyard F, Lefevre F, Letellier T, Francis O (2006) Modelling the global ocean tides: modern insights from FES2004. Ocean Dyn 56:394 415

Ma XC, Shum CK, Eanes RJ, Tapley BD (1994) Determination of ocean tides from the first year of Topex/Poseidon altimeter measurements. J Geophys Res 99:24809-24820

Munk WH, Cartwright DE (1966) Tidal spectroscopy and prediction. Philos Trans R Soc Lond Ser A 259:533-581

Park J-H, Watts DR (2006) Internal tides in the southwestern Japan/East Sea. J Phys Oceanogr 36:22-34
Pascual A, Faugre Y, Larnicol G, Le Traon P-Y (2006) Improved description of the ocean mesoscale variability by combining four satellite altimeters. Geophys Res Lett 33:L02611

Ray RD (1999) A global ocean tide model from Topex/Poseidon altimetry: GOT99.2, NASA Tech. Memo, vol 1999-209478. Goddard Space Flight Center, Greenbelt, p 58

Ray RD (2007) Propagation of the overtide $\mathrm{M}_{4}$ through the deep Atlantic Ocean. Geophys Res Lett 34:L21602

Ray RD, Mitchum GT (1996) Surface manifestation of internal tides generated near Hawaii. Geophys Res Lett 23:21012104

Ray RD, Ponte RM (2003) Barometric tides from ECMWF operational analyses. Ann Geophys 21:1897-1910

Ray RD, Bettadpur S, Eanes RJ, Schrama EJO (1995) Geometrical determination of the Love number $h_{2}$ at four tidal frequencies. Geophys Res Lett 22:2175 2178

Shum C-K and 16 coauthors (1997) Accuracy assessment of recent ocean tide models. J Geophys Res 102:25173-25194

Smylie DE, Hinderer J, Richter B, Ducarme B (1993) The product spectra of gravity and barometric pressure in Europe. Phys Earth Planet Inter 80:135-157

Spencer R, Vassie JM (1997) The evolution of deep ocean pressure measurements in the UK. Prog Oceanogr 40:423 435

Tierney CC, Parke ME, Born GH (1998) An investigation of ocean tides derived from along-track altimetry. J Geophys Res 103:10273-10287

Zhao Z, Alford MH (2009) New altimetric estimates of mode-1 $\mathrm{M}_{2}$ internal tides in the central North Pacific Ocean. J Phys Oceanogr 39:1669-1684 